УДК 821.161.1

\title{
ТОПОСЫ ЧЕЛОВЕЧЕСКОГО ЖИЛЬЯ В ПРОЗЕ И.А. БУНИНА: АВТОРСКАЯ МИФОПОЭТИКА И СЮЖЕТОСТРОЕНИЕ
}

\section{Евтушенко Эмилия Анатольевна}

к. филол. н., доцент

ФГБОУ ВО «Башкирский государственный университет»

Аннотация: В статье проводится анализ основополагающих подходов И.А. Бунина к созданию художественного пространства. На первый план выходят топосы человеческого жилья, их осмысление в аспекте авторской мифопоэтики и сюжетостроения, связи микрокосма и макрокосма, Универсума. Рассматриваются значения, композиционные функции, сюжетная роль топоса порога в ряде рассказов писателя.

Ключевые слова: пространство, дом, порог, микрокосм, макрокосм, символ, человек, мифопоэтика И.А. Бунина, сюжетостроение.

\section{TOPOS OF HUMAN HOUSING IN I. A. BUNIN'S PROSE: AUTHOR'S MYTHOPOETICS AND PLOT-BUILDING}

\section{Evtushenko Emilia Anatolyevna}

\begin{abstract}
The article analyzes the fundamental approaches of I.A. Bunin to the creation of an artistic space. The toposes of human housing, their interpretation in the aspect of the author's mythopoetics and plot construction, the connection between the microcosm and the macrocosm, the Universe come to the fore. The meanings, compositional functions, the plot role of the threshold topos in a number of the writer's stories are considered.
\end{abstract}

Key words: space, house, threshold, microcosm, macrocosm, symbol, human, mythopoetics of I.A. Bunin, plot building.

Художественное пространство прозаических произведений Ивана Алексеевича Бунина есть отражение особенностей бунинского видения мира и человека в нём, оно пронизано мифопоэтическими мотивами, наполнено архетипами, в нём сквозь «внешнее» «бытовое» всё время просвечивает, проступает «внутреннее», «онтологическое». Писатель по-особенному 
организует пространственно-временной континуум, скрепляет его лейтмотивами, повторяющимися «маркерами», варьируя их смыслы, уводя читателей в целую систему символических значений, помогая воспринимать сюжеты не как бытопись, но как тайнопись.

И.А. Бунин умеет тонко символизировать пространство, будь то лес, усадьба, сад, изба, путь, город, ярмарка. Он может постепенно расширять, раздвигать рамки места, как говорит Л.В. Крутикова, «непосредственного действия», например, Дурновки в «Деревне»: деревня - уездный город столица. Р.С. Спивак отмечает особое качество - «неподвижность» и художественного времени, и пространства - в том же произведении, что создаёт «горькую картину статичной жизни, которая при всей её суетливости, наполненности событиями не способна к обновлению», формирует структуру персонажей повести [7, с. 31]. По мысли М.С. Штерн, у художника происходит повторение и варьирование пространственных образов ночи, тумана, бури, света, тьмы, дома, образование лейтмотивов, создающих «сквозные ассоциативные сюжеты, оформляющие лирические коллизии»; символика пространства в «Тёмных аллеях» становится «одной из форм выражения авторского сознания» [8, с. 54]. М.А. Кочеткова говорит о «пространстве одиночества» бунинских героев, «пространстве» памяти, «пространственных координатах суходольской модели мира»; в повести «Суходол» происходит дальнейшее обогащение и видоизменение пространственных форм прозы писателя: «суходольская мифопоэтическая картина мира становится “пространственным” показателем векового, косного уклада и замкнутого, “отграниченного” от Всебытия существования хрущевского рода, а через него и всех знатных дворянских родов России» [4, с.5]. Пространственные реалии обладают у И.А. Бунина множеством значений, по воле автора они становятся «маркерами» сюжетных событий - и «внешних», и «внутренних», символизируются, открываются в осмысление человеческой судьбы, судьбы народа, страны, в прошлое, в будущее, в Вечность.

Особое значение в творчестве И.А. Бунина, как известно, имеет дом жилище человека, представленное спектром образов: рыбацкой хижиной, крестьянской избой, дворянской усадьбой. Е.Е. Ермакова называет «дом» особым континуумом, создавая который, писатель опирается на мировую традицию: дом есть символ «одной из форм Космоса и места Человека в нём» это архетип, «сакральный костяк, крестец целокупной реальности, imago mundi и одновременно способ жизни человека» [2]. Тайнопись дома, его 
метафизический, религиозный, фольклорный, философский смысл проступают через антиномические значения, бинарные оппозиции. С одной стороны, владение домом, привязанность, принадлежность и стремление к нему означают защиту, устойчивое положение в мире, очаг, семейную жизнь. С другой, отказ от дома, движение не «к нему», а «от него», означают паломничество, скитальничество, перемещение в мире, освобождение, стремление к высшей истине по архетипу «удалившегося Бога» (Deus absconditus) [2]. Отсутствие дома - глубокий автобиографический мотив для И.А. Бунина (тяжесть «бездомности» передана ещё в Евангелии от Луки: «Лисицы имеют норы, и птицы небесные - гнёзда, а Сын Человеческий не имеет, где преклонить голову» (IX, 58)). Эта ситуация осмысляется в ряде произведений писателя через распадение домашнего микрокосма на части,

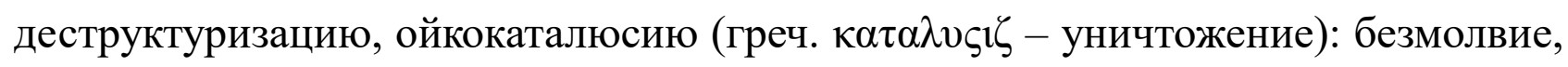
мертвенность, ветхость, заброшенность, покинутость, холод.

Наряду с окнами, полом, углами, печью, крыльцом важнейшей пространственной координатой дома в плане мифопоэтики становится у И.А. Бунина порог. Традиционные, закреплённые в культурах мира его значения - это пересечение границы в ситуациях входа и выхода, однако «пороговая» символика в авторском творчестве далеко не исчерпывается ими. Для героев И.А. Бунина важно преодоление пространственных рамок жилища, выход «вовне», и это не только выход физический, в мир природы, например, но и выход в новый этап жизни, макрокосм Универсума и др.

Анализ «пороговой» символики в творчестве И.А. Бунина невозможен без проникновения в фольклорно-мифологически традиции и историю. Изначально порог - бытовая реалия жизни разных народов, которые строили жилища. В фольклоре и художественной литературе он превращается в особенный топос, имеющий спектр символических, магических, онтологических, философских значений, функций. Как материальное выражение части «дома», он традиционно означает пограничность, разделение пространства на «своё» и «чужое», нарушения табу, запреты и разрешения, «прорастает» смыслами в событийный ряд сюжета, внутренний мир человека, его эмоции, переживания, перипетии судьбы, играет роль композиционного «маркера» и в итоге становится частью мифопоэтики и авторского стиля.

В «Энциклопедии символов» Дж. Купера находим подробную характеристику значений порога: «Порог - символизирует проход от профанного к сакральному, от внешнего профанного пространства к 
внутреннему сакральному пространству, вхождение в новый мир. Как граничный символ означает место встречи естественного и сверхъестественного, что ритуально определяется в церемонии "разрушения границ", заново определяющей пространственную структуру космоса, так же, как и новогодние церемонии заново определяют структуру времени. Тонуть в воде, войти в тёмный лес или в дверь в стене - это пороговые символы вхождения в опасную неизвестность. Весталки, богини девственности, - это пороговые богини, например, лары. Стражи порога, которых должно преодолеть, перед тем как идущий попадёт в священное место, - это драконы, змеи, чудовища, собаки, люди-скорпионы, львы и т.п. В физической и духовной реальности стражи препятствуют идущему зайти слишком далеко, идти слишком быстро, встретить или увидеть больше, чем он способен вынести в оккультном или эзотерическом знании» [6, с. 256].

В ряде культур мира порог - постоянное место невидимого «стража порога», способного задерживать, отводить непрошеных гостей, не пуская их в дом. Японцы до сих пор ритуально насыпают на пороги соль для защиты от духов мёртвых. В Европе пороги, дверные косяки традиционно украшаются защищающими жилище знаками. В русском языке отражены узуальные метафоры порога (не переступать порога; беда у порога, то есть близко; на пороге возмужания; на пороге зимы, то есть в её преддверии; переступить порог, то есть сделать решительный шаг); есть множество фольклорных примеров - паремий: загадок, пословиц, примет, суеверий о пороге (добрая слава до порога, а худая за порог; вот тебе Бог, а вот - порог; нельзя разговаривать через порог, что-то передавать через него, нельзя сидеть или стоять на пороге, поскольку можно потревожить обитателей мира мёртвых, накликать беду и др.).

А.А. Кононенко в «Энциклопедии славянской культуры, письменности и мифологии» характеризует порог как символическую «межу» между жилищем и внешним миром, амбивалентный локус границы для нечистой силы и в то же время место пребывания нечисти: «На пороге совершали разные обрядовые действа. К примеру, били порог дома веником, чтобы прогнать чужого домового; под порогом бани закапывали чёрного петуха, чтобы задобрить банника; на пороге дома или хлева рубили старый веник, чтобы прогнать болезнь, немощь; на пороге провозглашали заговоры, делали зарубки освящённым ножом от нечисти, кропили святой водой...» [3]. .

По теории хронотопа М.М. Бахтина, порог - особая часть объективной 
реальности: «Назовём здесь ещё такой, проникнутый высокой эмоциональноценностной интенсивностью, хронотоп, как порог; он может сочетаться и с мотивом встречи, но наиболее существенное его восполнение - это хронотоп кризиса и жизненного перелома. Самое слово «порог» уже в речевой жизни (наряду с реальным значением) получило метафорическое значение и сочеталось с моментом перелома в жизни, кризиса, меняющего жизнь решения (или нерешительности, боязни переступить порог). В литературе хронотоп порога всегда метафоричен и символичен, иногда в открытой, но чаще в имплицитной форме» [1]. Исследователь выделяет в литературных произведениях три категории образов пространства - «дом» (замкнутое пространство), «простор» (пространство открытое) и «порог», обозначающий границу между пространством «простора» и пространством «дома». Благодаря своей богатейшей семантике и связям с древними традициями, архетипами порог может символически обозначать завязку сюжета, кульминацию или развязку, состояния души героя, предвосхищать неожиданные переломы в развитии событий, обогащать поэтику, делать её многослойной, как это происходит у И.А. Бунина.

В рассказе «Танька» в память Таньки особенно врезается продажа лошади, это событие становится для неё сильнейшим эмоциональным потрясением: «анчихристы» в телеге, бегущий за лошадью отец и мать, стоящая на пороге избы и голосящая [4] (эмоционально-ценностная интенсивность топоса, по М.М. Бахтину).

«На чужой стороне»: И.А. Бунин описывает картину народной жизни суматоху последних приготовлений к церкви, мужиков в новых сапогах, наряженных девок и баб. Церковь освещается, толкотня, ударяет колокол, входит священник: «Воскресение твое, Христе спасе, ангели поют на небеси...», мужики стоят в темноте, опускаются на колени, торопливо крестятся, «то надолго припадая лбами к nорогу, то жадно и скорбно смотря в глубину освещённой залы, на огни и иконы, подняв свои худые лица с пепельными губами, свои голодные глаза...» [4] (порог как граница между профанным и сакральным).

В «Велге» хижина отца героини находится вдалеке от рыбачьего селенья, и в часы прилива море достигает её порога; Велга не боится бури, она вместе с отцом выходит на мокрый порог хижины, скатывает на ветру сети, а потом вбегает в воду, которая обдаёт её босые ноги шипящей серой пеной; свободолюбивая Велга может сидеть на пороге весь день, скорбно сдвинув 
брови [9]. Порог ветхого жилища отделяет закрытое пространство хижины от огромного моря, символизирует постоянный переход Велги к свободной морской стихии, родство и слияние с ней.

В рассказе «Эпитафия» деревня пустеет, её покидают люди, они распродают свой скудный скарб, забивают досками окна изб. Зарастает высокой сорной травой выгон, здесь больше не пасётся скот, и глухая крапива поднимается у порогов некогда звучавших человеческими голосами изб. «Степь вокруг мертва, а десяток уцелевших изб можно издалека принять за кибитки кочевников, покинутые в поле после битвы или чумы» [9]. Неоднократно встречающаяся у И.А. Бунина деталь - дикие травы подходят к порогу некогда населённых людьми жилищ, символизируя запустение, наступление природы на некогда живое бытие человека. Аналогичную картину рисует писатель в рассказе «Золотое дно»: в большой деревне тихо; «скучно лоснится на солнце мелкий длинный пруд жёлтой глинистой водой; баба возле навозной плотины лениво бьёт вальком по мокрому серому холсту... Сад ещё до сих пор густ и живописен, и, как на идиллическом пейзаже, стоит за ним серый большой дом под бурой, ржавой крышей. Но усадьба, усадьба! Целая поэма запустения! ...и всюду, к самым порогам, подступили лопухи и глухая крапива» [9]. Пороги, пороги, пороги - они выделяются в структуре повествования

В рассказе «У истока дней» И.А. Бунин переносит героя-повествователя в далёкое детство. Он вспоминает непередаваемую тоску, предчувствие чего-то неотвратимого, какую-то возню, звуки испуганных, торопливых голосов, тревожный стук открывающихся и закрывающихся дверей и, наконец, ужасный сдавленный крик, заново переживает всё это. «Растворилась дверь... Потом... воспитатель мой повёл меня в ту, слабо освещённую синей лампадкой комнату, где на ломберном столе, покрытом простынею, лежала кукла в розовом платьице... Помню, как мы остановились на пороге этой комнаты и, перекрестившись, поклонились в угол, лампадке и этой кукле...» [9]. Дело в том, что в доме, рядом с рассказчиком-ребёнком, умирает маленькая девочка. За порогом - уже не жизнь, а что-то чужеродное, искусственное, противоестественное. Вот почему порог в воспоминаниях повествователя остаётся «гранью», границей, разделяющей два пространства - жизнь и смерть.

В рассказе «Маленький роман» показана переломная ситуация. Она стоит на пороге, в светлом треугольнике парусинового шатра, и, не повышая голоса, спокойно говорит ему: «- Прощайте» [9]. И это последнее слово, которое слышит от неё герой. Ситуация «на пороге» означает неотвратимость 
расставания, переход в новый этап жизни, друг без друга. У неё есть жених, она скоро должна стать графиней Эль-Маммуна, потому что, по её словам, «его боится». Это ещё одна трагедия любви, трагедия несовпадения: «Дорогой мой, - писала она мне через четыре месяца после этого, - не вините меня, что я исчезла, даже не предупредив вас. Он был в тысячу раз сильнее меня. Я потеряла волю, упустила страшный момент, когда ещё можно было все порвать. Теперь у меня нет уже почти никаких надежд на встречу с вами. Да и как бы мы встретились?» [9].

В рассказе «Птицы небесные» студент вечером долго ходит по залу дома, читает Юнга, чтобы отвлечься, а потом, часов в десять, выходит наружу взглянуть на восход Близнецов: «И на пороге сеней оторопел: показалось, что свету божьего не видно, - так гулко шумел сад от морозной бури, так бешено несла позёмка. Но сад чётко чернел над её непрерывно несущимися вихрями, и звёзды огнём горели на чёрном чистом небе» [9]. И.А. Бунин показывает: за порогом дома открывается мифопоэтическое пространство, таинственное, наполненное знаками. Перед ним герой застывает на пороге. Топос, как это нередко бывает у писателя, связан с психологическим состоянием человека.

На наш взгляд, топос порога наиболее сложно представлен в рассказе «При дороге». Парашка вступает в пору взросления, это связано с переживанием душевной смуты, сладкой и одновременно мучительной тоски, ожидания чего-то опасного и неизведанного, какого-то незримого «порога». Её излюбленное место - порог родительской избы, где она часто сидит, устремив взгляд на вечерние поля, голый простор дороги, смотрит на молодого мещанина на белом горбоносом киргизе. «Любимым местом её был порог, по часам сидела она на нём, чуть склонив к плечу голову. Далеко куда-то, в счастливую страну, направлялись все те, что порою проезжали, проходили мимо» [9]. После того как мещанин впервые, прощаясь, протягивает ей руку, её обжигает стыдом, точно это знак, начало их тайного сближения. «Она по целым дням стояла на пороге и нетерпеливо, с настойчивостью и требовательностью подростка, ждала его» [9]. И он возвращается, причём это событие «маркируется» порогом: «- Здорово! - смело сказал мещанин, появляясь на nороге. - Ловко попал, прямо под чай... - Не веришь? - сказал он, осторожно обнимая её. - А я правду говорю. Я в тебя влюбился ещё в тот раз, когда гурт гнал...» [9]. Ощущение «нерушимой связи и тайны», счастья и нежности, первого поцелуя, близости - всё это лишь у неё, простой крестьянки, ему же Парашка нужна в корыстных целях, цинично: чтобы свести с отцовского двора 
двух кобыл, а затем бежать с ним в Ростов. Порог в жизни Парашки означает градацию её погружения в омут страсти, инициацию первого любовного опыта, переломные моменты её личной истории, для подлеца же это граница, пересекая которую, он вторгается в чужую жизнь, перемещается между «своим» миром и «чужим», при этом зная правду, без иллюзий и дурмана.

Таким образом, жилище человека и, в частности, топос порога - это в мифопоэтике И.А. Бунина часть системы метаязыка архитектуры и - шире художественного пространства, объединяющего вещное, бытовое и духовное, метафизическое, судьбоносное. Спектр смыслообразующих и композиционных значений порога в прозе писателя необыкновенно широк: традиционная граница между «своим» и «чужим», микрокосмом и макрокосмом, жизнью и смертью, «профанным» и «сакральным», «точка» соприкосновения или, наоборот, разъединения, перехода одного в другое, «сигнал», предупреждающий о близкой опасности, перелом в судьбе. Топос порога участвует в конструировании писателем сюжета: обозначает скрытые связи между героями, связывает части повествования, событийных цепочек, образует мифопоэтический подтекст.

\section{Список литературы}

1. Бахтин М.М. Формы времени и хронотопа в романе. Очерки по исторической поэтике. - URL: https://philolog.petrsu.ru/filolog/lit/bahhron.pdf (дата обращения: 19.04. 2021 г.).

2. Ермакова Е.Е. Ступень «дома» в поэзии Ивана Алексеевича Бунина // TOПОС. Литературно-философский журнал. - 21/10/2002. - URL: https:// www.topos.ru/article/615 (дата обращения: 20.06.2021 г.).

3. Кононенко А.А. Энциклопедия славянской культуры, письменности и мифологии. - URL: https://history.wikireading.ru/406621 (дата обращения: 15.04.2021).

4. Кочеткова М.А. Художественное пространство в рассказах И.А. Бунина 1890-х-1910-х гг. и в повестях «Деревня» и «Суходол». Автореферат диссертации на соиск. уч. степени канд. филол. наук. - Ульяновск, 2005. - 20 c. - URL: https://www.dissercat.com/content/khudozhestvennoeprostranstvo-v-rasskazakh-ia-bunina-1890-kh-1910-kh-gg-i-v-povestyakh-derev (дата обращения: 20.05.2021 г.).

5. Крутикова Л.В. «Деревня» И.А. Бунина (Человек, народ, Россия) / Иван Бунин и литературный процесс начала XX века (до 1917 года): Межвуз. 
сб. науч. тр. / Ленингр. гос. пед. ин-т им. А. И. Герцена, Мурм. гос. пед. ин-т; [Редкол.: Г. А. Голотина и др.]. - Л.: ЛГПИ, 1985. - 129 с.

6. Купер Дж. Энциклопедия символов. Серия «Символы». Книга IV. М.: Ассоциация Духовного Единения «Золотой Век», 1995. - 401 с.

7. Спивак Р.С. Жанровая структура и авторская концепция в «Деревне» И.А. Бунина / Иван Бунин и литературный процесс начала XX века (до 1917 года): Межвуз. сб. науч. тр. / Ленингр. гос. пед. ин-т им. А. И. Герцена, Мурм. гос. пед. ин-т; [Редкол.: Г. А. Голотина и др.]. - Л.: ЛГПИ, 1985. - 129 с.

8. Штерн М.С. Проза И. А. Бунина 1930 - 1940-х годов: Жанровая система и родовая специфика: диссертация ... доктора филологических наук: 10.01.01. - Омск, 1997. - 488 c. - URL: https://search.rsl.ru/ru/record/ 01000191103 (дата обращения: 20.06.2021 г.).

9. Lib.Ru/Классика: Бунин Иван Алексеевич: Собрание сочинений. URL: http://az.lib.ru/b/bunin_i_a/ (дата обращения: 20.04.2021 г.).

(C) Э.А. Евтушенко, 2021 